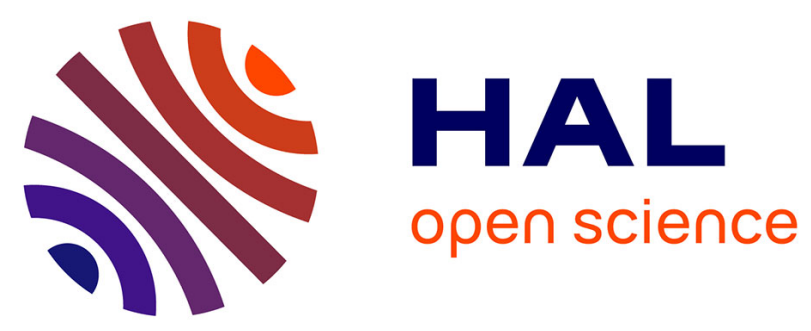

\title{
P-Stereogenic Phosphonates via Dynamic Kinetic Resolution: A Route towards Enantiopure Tertiary Phosphine Oxides
}

\author{
Aabid Mohd, Thippani Anitha, Kallu Rajender Reddy, Joanna \\ Wencel-Delord, Françoise Colobert
}

\section{To cite this version:}

Aabid Mohd, Thippani Anitha, Kallu Rajender Reddy, Joanna Wencel-Delord, Françoise Colobert. P-Stereogenic Phosphonates via Dynamic Kinetic Resolution: A Route towards Enantiopure Tertiary Phosphine Oxides. European Journal of Organic Chemistry, 2019, 10.1002/ejoc.201901475 . hal02410836

\section{HAL Id: hal-02410836 \\ https://hal.science/hal-02410836}

Submitted on 15 Dec 2020

HAL is a multi-disciplinary open access archive for the deposit and dissemination of scientific research documents, whether they are published or not. The documents may come from teaching and research institutions in France or abroad, or from public or private research centers.
L'archive ouverte pluridisciplinaire HAL, est destinée au dépôt et à la diffusion de documents scientifiques de niveau recherche, publiés ou non, émanant des établissements d'enseignement et de recherche français ou étrangers, des laboratoires publics ou privés. 


\title{
P-Stereogenic Phosphonates via Dynamic Kinetic Resolution: A Route towards Enantiopure Tertiary Phosphine Oxides
}

\author{
Aabid Mohd, ${ }^{[a]}$ Thippani Anitha, ${ }^{[\mathrm{b}]}$ Kallu Rajender Reddy, ${ }^{[\mathrm{b}]}$ Joanna Wencel-Delord, ${ }^{*[\mathrm{a}]}$ and \\ Françoise Colobert*[a]
}

\begin{abstract}
Asymmetric synthesis of P-stereogenic phosphonates presents a great challenge. Following this target we disclose herein a DKR strategy towards the O-P coupling reaction between an easily accessible enantiopure phenol bearing a chiral sulfinyl auxiliary and a commercially available or easily accessible racemic $\mathrm{H}$-phosphinate. Although moderate to high chiral
\end{abstract}

induction is achieved, several diastereopure phosphonates can be afforded either by crystallization or flash chromatography. Thus accessed optically pure $P$-stereogenic precursors may be used as appealing building blocks to rapidly assembly original privileged scaffolds as illustrated via the synthesis of a chiral ligand such as PAMPO.
P-stereogenic organophosphorus compounds are an important class of valuable products with widespread applications particularly in asymmetric catalysis. ${ }^{[1]}$ Over the last twenty years the synthesis of molecules with a P-stereogenic center has received significant attention. ${ }^{[2]}$ Accordingly, several modern approaches such as enantioselective metal-couplings and $\mathrm{C}-\mathrm{H}$ activation based reactions have been reported. ${ }^{[3]}$ Besides, the development of chiral separation techniques provided an alternative approach. ${ }^{[4]}$ However, these transformations are generally strongly limited by the generation of only specific $P$-stereogenic scaffolds and/or are inadequate for a large-scale synthesis. Accordingly, diastereoselective synthesis of $P$-stereogenic compounds, calling for a use of an enantiopure auxiliary, is still the most general and widely applied methodology to build up an array of $P$-stereogenic molecules. Indeed, already in 1967 Mislow had illustrated a great potential of cheap and abundant menthol for the resolution of tertiary phosphines. ${ }^{[5]}$ Due to the versatility of this diastereoselective approach, this method greatly contributed to the design of $P$-stereogenic ligands such as DiPAMP or Mini-Phos, and their applications in asymmetric catalysis (Scheme 1a). ${ }^{[6]}$ Later Jugé showed that chiral amines such as ephedrine were also very powerful chiral auxiliaries delivering the corresponding $P$-stereogenic oxazaphospholidine in high yield and diastereoselectivity (Scheme 1b). ${ }^{[7]}$ Similar strategies developed by Han in 2013 and Framery in 2015 involved

[a] Laboratoire d'Innovation Moléculaire et Applications (UMR CNRS 7042), Université de Strasbourg / Université de haute Alsace, ECPM, 25 Rue Becquerel, 67087, Strasbourg, France

E-mail: francoise.colobert@unistra.fr wenceldelord@unistra.fr

[b] Catalysis and Fine chemicals Division, CSIR-Indian Institute of Chemical Technology,

Tarnaka, Hyderabad, Telangana State -500 007, India

E-mail: rajender@iict.res.in

rajenderkallu@gmail.com the use of respectively a benzoxazaphosphinine- 2 oxide ${ }^{[2 g]}$ and an oxaphospholidine obtained from D-glucosamine ${ }^{[8]}$ as chiral phosphinyl transfer agents. Importantly an alternative protocol using enantioselective deprotonation of aryldimethyl phosphine boranes when using alkyllithium reagents in combination with (-)-sparteine chiral ligand was disclosed by Evans (Scheme 1c). ${ }^{[9]}$

Regarding the great importance of P-stereogenic compounds in pharmaceutical and agrochemistry, but also their key importance in asymmetric synthesis, the development of new synthetic routes for the synthesis of $P$-stereogenic compounds is still a tempting challenge in organic chemistry. In particular, designing a strategy towards a P-stereogenic "platform", featuringastrongmodularityandfacileconvertibilityintoanarrayofenantiopure molecules would be a significant advance. Following this challenge, enantioenriched $P$-stereogenic phosphonates bearing two different alkoxy substituents appear as excellent candidates that could undergo the chemoselective and sequential functionalization of both alkoxy substituents, paving the way towards a broad array of enantiopure tertiary phosphine oxides. Besides, the absolute configuration of the newly accessed scaffolds could also be controlled by a simple modification of the order of the sequential functionalization. However despite their great synthetic value, enantioenriched $P(O) R^{3}\left(O R^{1}\right)\left(O R^{2}\right)$ scaffolds remain elusive (Scheme $\left.1 d\right)$.

To address this synthetic challenge, we hypothesized that a direct and stereoselective O-P coupling could be envisioned between a phenol bearing a chiral auxiliary in ortho-position and a commercially available or easily accessible racemic $\mathrm{H}$ phosphinate as an organophosphorus precursor. Interestingly, as $\mathrm{H}$-phosphinates are prone to epimerisation, ${ }^{[4 \mathrm{~b}]}$ such a coupling could potentially occur via Dynamic Kinetic Resolution Mechanism (DKR) thus allowing conversion of a racemic product into a high value-added diastereoenriched $P$-compound. As far as the choice of the chiral auxiliary is concerned, we surmised that a sulfoxide moiety could be an efficient source of 


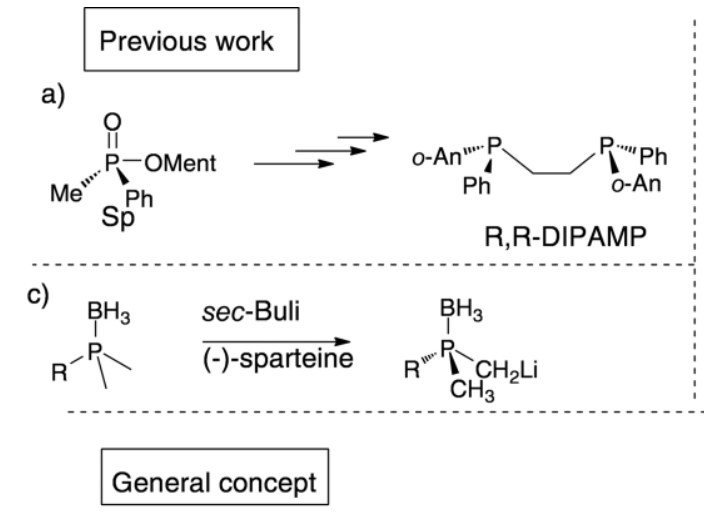

d)

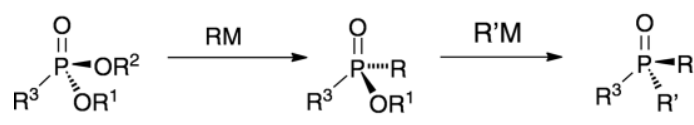

b) Jugé's Strategy

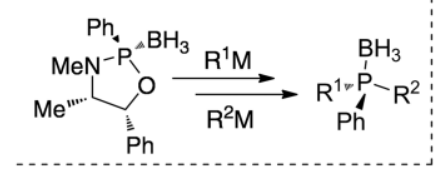

Han's Strategy

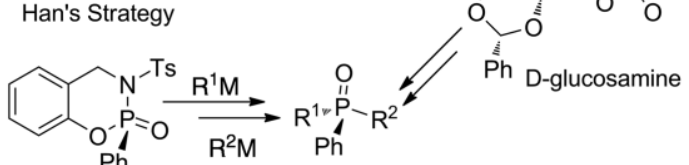

e)

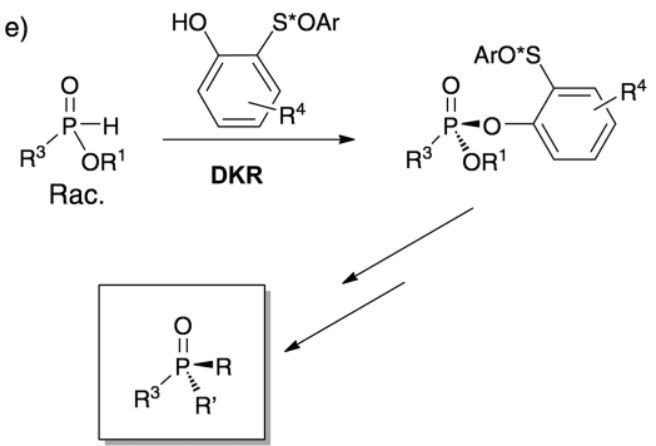

Scheme 1. Synthesis of $P$-stereogenic products.

chirality. Indeed, the sulfoxide auxiliary precursors 1) are straightforwardly accessible on large scale from cheap precursors, 2) may be easily installed on the phenol coupling partner and 3) their high important optical stability under various conditions should warrant recycling of the phenol-sulfoxide motif while performing final functionalization of the $P$-stereogenic product (Scheme 1e). Thus accessed optically pure phosphonates could potentially be transformed into a variety of original $P$-stereogenic scaffolds by using organolithium or Grignard's reagents with a concomitant release of the enantiopure phenol bearing chiral sulfoxide. Besides, if chiral phenol is used as the auxiliary, the diastereomeric $\mathrm{P}(\mathrm{O}) \mathrm{R}\left(\mathrm{OR}^{1}\right)(\mathrm{OAr})$ obtained present two sites for further functionalization and if chemoselective substitution of (OAr) and ( $\left.\mathrm{OR}^{1}\right)$ can be conducted, a particularly large panel of $P$-stereogenic compounds could be accessed (Scheme 1e).

Targeting the foreseen O-P couplings, we drew the inspiration from the Atherton Todd (AT) reaction, a classical synthetic method to prepare phosphoramidates, phosphonates and other organophosphorus derivatives via X-P coupling between an organophosphorus precursor including $\mathrm{H}$-phosphinate/ $\mathrm{H}$ phosphonate, and a nucleophile such as amine/alcohol. ${ }^{[10]}$ This reaction typically occurs in carbon tetrachloride and requires addition of a base, usually a trialkylamine. The (AT) reaction proceeds through inversion of configuration on $\mathrm{P}$ atom (Scheme 2). ${ }^{[11]}$ Indeed the first step corresponds to the formation of a chlorophosphate intermediate and proceeds through

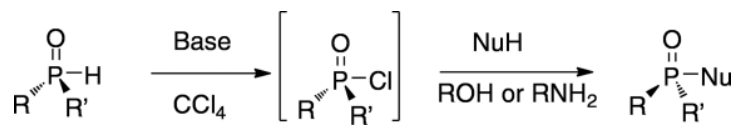

Scheme 2. Atherton Todd reaction. retention of configuration on $\mathrm{P}$ atom, while the second step i.e. nucleophilic substitution takes place with inversion of configuration on $\mathrm{P}$ atom.

Following these considerations, we have designed phenols $\mathbf{2 A}-\mathbf{C}$, bearing $p$-tolyl sulfinyl and the more hindered tert-butylsulfinyl and adamantly moieties respectively as chiral inductors for a diastereoselective O-P coupling reaction. Accordingly the enantiopure phenols $\mathbf{2}$ bearing the sulfinyl auxiliary were synthesized in high overall yields following a general strategy involving 1) the protection of o-bromophenol as a MOM ether, 2) a bromine/ lithium exchange followed by condensation with (S)-p-tolylmenthyl sulfinate (A), (S)-(tert-butyl)-tertbutane thiosulfinate (B) or adamantan-1-yl-adamantane-1-sulfinothioate (C) and finally 3 ) deprotection with $\mathrm{HCl}$ and crystallization (Scheme 3). ${ }^{[12]}$

With these chiral phenols in hand, we first performed the coupling between the commercially available racemic ethylphenyl H-phosphinate 1a and (S)-2-( $p$-tolylsulfinyl) phenol 2A. Under the standard reaction conditions, [1 equivalent of (S)2-( $p$-tolylsulfinyl) phenol $\mathbf{2 A}, 2$ equivalents of triethylamine in carbon tetrachloride at room temperature under air] and using 2 equivalents of ethylphenyl $\mathrm{H}$-phosphinate $\mathbf{1} \mathbf{a}$, the desired O-P coupling reaction proceeded well, providing the corresponding product $\mathbf{3 a A}$ in $83 \%$ isolated yield, but with a low 55:45 diastereomeric ratio measured by ${ }^{31} \mathrm{P}$ NMR of the crude reaction mixture (Table 1 , entry 1 ). Although the reaction is equally efficient at lower temperature, ie. $-20{ }^{\circ} \mathrm{C}$, no improvement in diastereoselectivity was observed (Table 1 , entry 2 ). This modest chiral induction prompted us to use the more hindered (S)-2(tert-butylsulfinyl)phenol 2B and its coupling with ethylphenyl $\mathrm{H}$-phosphinate 1a proceeded with full conversion furnishing $\mathbf{3 a B}$ within $3 \mathrm{~h}$ and with an increased diastereomeric ratio of 71:29 (entry 3). Detailed optimization of the reaction conditions 
revealed that: 1) the coupling was highly water-sensitive and thus, the diastereoeselectivity was improved up to 83:17 while adding molecular sieves (entry 4); 2) the replacement of toxic $\mathrm{CCl}_{4}$ with $\mathrm{THF}$, toluene, dioxane, $\mathrm{Et}_{2} \mathrm{O}$ or DME in presence of 10 equivalents of $\mathrm{CCl}_{4}$ did not hamper the reactivity and full conversion of $\mathbf{1} \mathbf{a}$ to $\mathbf{3} \mathbf{a B}$ was observed despite a slightly decreased stereoselectivity ( $d r 77: 23$, entries $5-9$ ). Of note is that THF was selected as the solvent of choice for further screening of the other reaction parameters; 3 ) decreasing reaction's concentration positively impacted the chiral induction and the optimal results in terms of efficiency and diastereoselectivity, ie. $d r$ of 83:17 and full conversion within $2 \mathrm{~h}$, were reached for a concentration of $0.05 \mathrm{M}$ (entries $10-11)$; 4) the use of 4 equivalents of diisopropylethylamine instead of $\mathrm{Et}_{3} \mathrm{~N}$ allowed to get an excellent $d r$ of 90:10 although prolonged reaction time up to $24 \mathrm{~h}$ was required (entry 12). Of note is that other bases, such as DBU, DMAP and 2,6-lutidine performed poorly (entries 13-15). Finally, to further increase the stereoinduction during this AT reaction we evaluated the potential of even more sterically demanding phenol-sulfoxide $\mathbf{2 C}$, bearing an adamantyl substituent at S-atom. Disappointingly, no improvement in the chiral induction was observed, while the overall efficiency of the coupling decreased (entry 16). Accordingly, under the optimized reaction conditions, that is, using 2 equivalents of racemic ethylphenyl $\mathrm{H}$-phosphinate, 1 equivalent of enantiopure (S)-2-(tert-butylsulfinyl)phenol, 10 equivalents of carbon tetrachloride, 4 equivalents of diisopropylethylamine and $75 \mathrm{mg} / \mathrm{mL}$ of molecular sieves (MS) in THF under argon at room temperature for about $24 \mathrm{~h}$, the maximum diastereomeric ratio of $90: 10$ was achieved with $85 \%$ yield.

Subsequently, we hypothesized that the low configurational stability of the $\mathrm{H}$-phosphinates should facilitate their in situ racemisation in the reaction mixture. Accordingly, the overall transformation might occur via Dynamic Kinetic Resolution scenario. In order to validate this assumption, this O-P coupling was performed using equimolar amounts of $\mathbf{1 a}$ and $\mathbf{2 B}$. As ex-

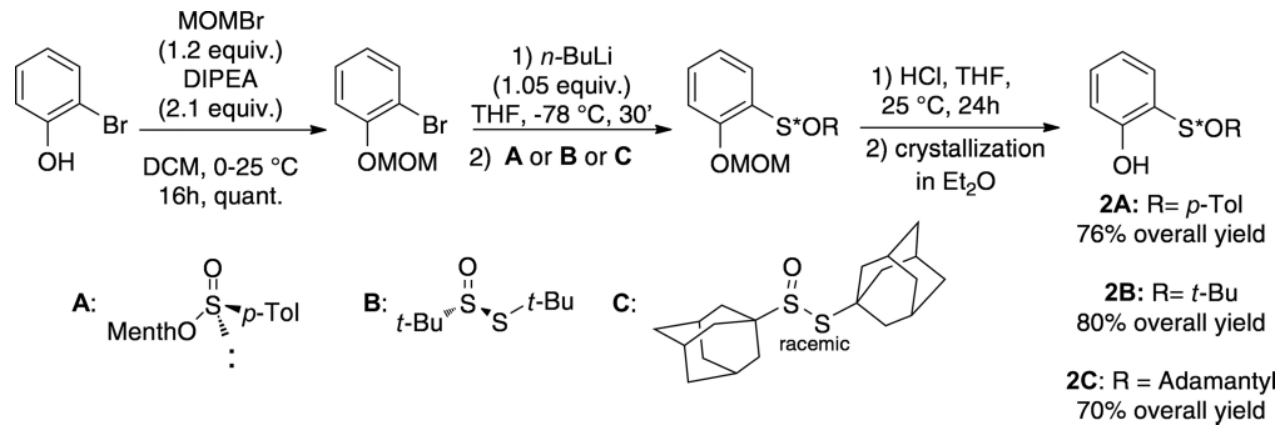

Scheme 3. Synthesis of enantiopure phenols 2 .

Table 1. Atherton Todd O-P coupling reaction. Scheme of Table 1 in the middle of the page

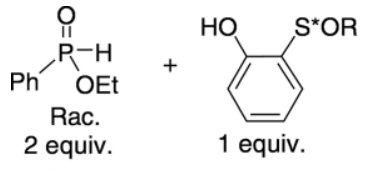

1a $2 A-C$

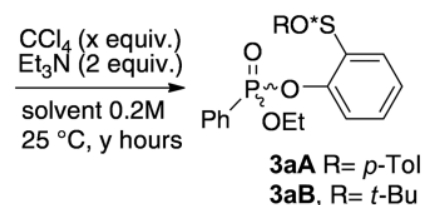

$3 \mathrm{aB}, \mathrm{R}=t-\mathrm{Bu}$

3aC, $\mathrm{R}=$ Adam

\begin{tabular}{|c|c|c|c|c|c|c|c|}
\hline Entry & $\mathrm{R}$ & Base & $\mathrm{CCl}_{4}$ ( $x$ equiv.) & solvent & $Y$ hours & Yield $^{[\mathrm{a}]}[\%]$ & $d r$ \\
\hline 1 & $p$ Tol & $\mathrm{Et}_{3} \mathrm{~N}$ & - & $\mathrm{CCl}_{4}$ & 24 & 90 & $55: 45$ \\
\hline $2^{[\mathrm{b}]}$ & pTol & $\mathrm{Et}_{3} \mathrm{~N}$ & - & $\mathrm{CCl}_{4}$ & 24 & 90 & $58: 42$ \\
\hline 3 & $\mathrm{tBu}$ & $\mathrm{Et}_{3} \mathrm{~N}$ & - & $\mathrm{CCl}_{4}$ & 3 & $>95$ & $71: 29$ \\
\hline $4^{[c]}$ & $t \mathrm{Bu}$ & $\mathrm{Et}_{3} \mathrm{~N}$ & - & $\mathrm{CCl}_{4}$ & 2 & $>95$ & $83: 17$ \\
\hline $5^{c}$ & $t \mathrm{Bu}$ & $\mathrm{Et}_{3} \mathrm{~N}$ & 10 & THF & 1 & $>95$ & $77: 23$ \\
\hline $6^{c}$ & $t \mathrm{Bu}$ & $\mathrm{Et}_{3} \mathrm{~N}$ & 10 & Toluene & 1 & $>95$ & $77: 23$ \\
\hline $7^{c}$ & $t \mathrm{Bu}$ & $\mathrm{Et}_{3} \mathrm{~N}$ & 10 & $\mathrm{Et}_{2} \mathrm{O}$ & 1 & $>95$ & $77: 23$ \\
\hline $8^{c}$ & $t \mathrm{Bu}$ & $\mathrm{Et}_{3} \mathrm{~N}$ & 10 & dioxane & 1 & $>95$ & $77: 23$ \\
\hline $9^{c}$ & $t \mathrm{Bu}$ & $\mathrm{Et}_{3} \mathrm{~N}$ & 10 & DME & 1 & $>95$ & $77: 23$ \\
\hline $10^{[c, d]}$ & $t \mathrm{Bu}$ & $\mathrm{Et}_{3} \mathrm{~N}$ & 10 & THF & 2 & $>95$ & $83: 17$ \\
\hline $11^{[c, e]}$ & $t \mathrm{Bu}$ & $\mathrm{Et}_{3} \mathrm{~N}$ & 10 & THF & 6 & 90 & $83: 17$ \\
\hline $12^{[\mathrm{c}, \mathrm{d}, \mathrm{f}]}$ & $t \mathrm{Bu}$ & $i \mathrm{Pr}_{2} \mathrm{EtN}$ & 10 & THF & 24 & $>95$ & $90: 10$ \\
\hline $13^{[c, d]}$ & $t \mathrm{Bu}$ & DBU & 10 & THF & 1 & $>95$ & $50: 50$ \\
\hline $14^{[c, d]}$ & $t \mathrm{Bu}$ & DMAP & 10 & THF & 2 & 85 & $50: 50$ \\
\hline $15^{[\mathrm{c}, \mathrm{e}]}$ & $t \mathrm{Bu}$ & lutidine & 10 & THF & 2 & 0 & - \\
\hline $16^{[c, d, f]}$ & Adam & $i \mathrm{Pr}_{2} \mathrm{EtN}$ & 10 & THF & 24 & 67 & $90: 10$ \\
\hline $17^{[c, d, f, g]}$ & $t \mathrm{Bu}$ & $i \mathrm{Pr}_{2} \mathrm{EtN}$ & 10 & THF & 24 & 80 & $83: 17$ \\
\hline
\end{tabular}

[a] yield determined by ${ }^{1} \mathrm{H}$ NMR. [b] $-20{ }^{\circ} \mathrm{C}$. [c] With molecular sieves (75mg/mL). [d] $0.05 \mathrm{M}$. [e] $0.025 \mathrm{M}$. [f] $\mathrm{PPr}_{2}$ EtN (4 equiv.). [g] 1 equiv. of $1 \mathrm{a}$ was used. 
pected, we were delighted to obtain the desired product in $80 \%$ yield and 83:17 $d r$ unambiguously suggesting the dynamic kinetic resolution outcome (Table 1, entry 17). Changing several reaction parameters did not allow improving the diastereoselectivity. This DKR scenario could be explained based on recently reported DFT studies of the racemization of alkylphenyl $\mathrm{H}$-phosphinates. ${ }^{[13]}$ They proposed that in presence of an alcohol (i.e. our enantiopure ortho sulfinylphenol 2), pentavalent intermediates may be generated allowing the racemization through pseudorotation (Scheme 4).

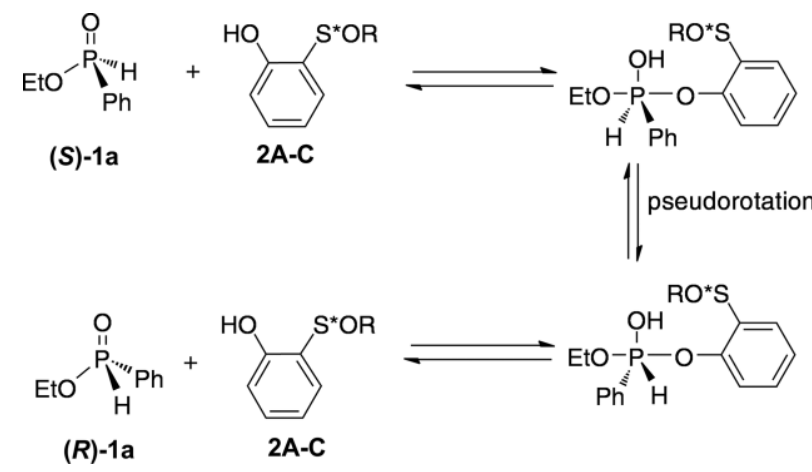

Scheme 4. Speculative mechanism of the racemization of alkylphenyl H-phosphinates.

With the optimized conditions in hand, the scope of this reaction was explored using different racemic $\mathrm{H}$-phosphinates, $^{[4 b, 14]}$ secondary phosphine oxides ${ }^{[14 f]}$ as well as differently substituted (S)-2-(tert-butylsulfinyl) phenols. ${ }^{[12 b]}$

The AT reaction proceeds smoothly for a wide variety of $\mathrm{H}$-phosphinates as well as for the secondary phosphine oxides. In general, as the steric hindrance of the alkoxy group attached to $\mathrm{P}$ atom in $\mathbf{H}$-phosphinates increases (3aB-3gB, Table 2), yields and diastereoselectivities of the reaction decrease. More sterically hindered $\mathrm{H}$-phosphinates such as isopropyl-, cyclohexyl-, tert-butyl-, and adamantylphenyl H-phosphinates were converted into the corresponding AT products 3dB (64\%, 77:23 $d r), 3$ eB $(67 \%, 60: 40 d r), 3$ fB (60\% NMR yield, 60:40 dr) and 3gB $(68 \%, 50: 50 d r)$ with lower yields and diastereoselectivities. Of note is that this surprisingly low chiral induction observed for the coupling of the adamantyl-substituted $\mathbf{1} \mathbf{g}$ does not arise from the slow racemization of the $\mathrm{H}$-phosphinate (increased configurational stability of $\mathbf{1} \mathbf{g}$ at room temperature may be expected) as no improvement was reached when performing the coupling in presence of 2 equivalents of $\mathbf{1} \mathbf{g}$ and decomposition occured while conducting the reaction at $80^{\circ} \mathrm{C}$.

Next we explored the modification of the aromatic or aliphatic substituent attached to $\mathrm{P}$ atom in $\mathrm{H}$-phosphinate. With a naphthyl group the AT product $\mathbf{3 h \mathbf { B }}$ was obtained in similar yield and diastereomeric ratio (72\%, 82:18 dr). However with sterically hindered cyclohexyl group the yield decreased drastically and a slightly lower diastereoselectivity was obtained as well (3iB, 34\%, 78:22 dr). Moreover, in case of ethyl methylphosphinate, $\mathbf{1} \mathbf{j}$, the corresponding product $\mathbf{3} \mathbf{j} \mathbf{B}$ was furnished in good yield and moderate diastereoselectivity (3jB, 80\%, 70:30 $d r)$. Finally, substitution pattern of the phenol-sulfoxides $\mathbf{2}$ was investigated. In case of substrates $\mathbf{2 D}-\mathbf{F}$, the reaction proceeded
Table 2. Scope for O-P coupling reaction.

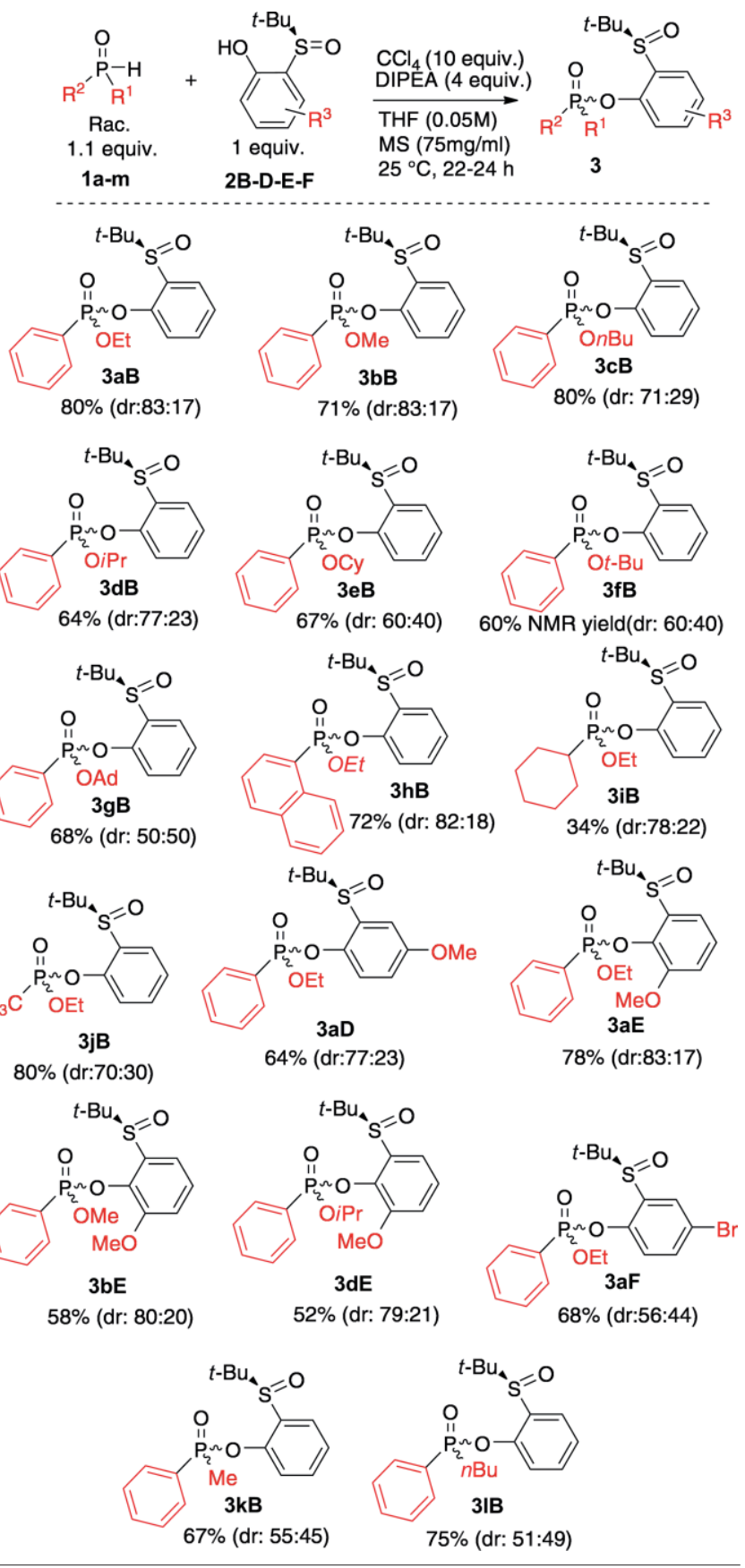

equally well, providing the corresponding products $3 \mathrm{aD}(64 \%$, $77: 23 d r)$, 3aE $(78 \%, 83: 17 d r)$, 3bE $(58 \%, 80: 20 d r)$, 3dE $(52 \%$, $79: 21 d r)$ and $3 \mathrm{aF}(68 \%, 56: 44 d r)$ bearing methoxy or bromine substituent in ortho- or para-positions. Nevertheless, phenol bearing a methyl group in ortho position was unreactive in this O-P coupling, even at higher temperature, showing that the more hindered phenols were difficult to react with a H-phosphinate substrate. Secondary phosphine oxides also underwent the O-P coupling reaction smoothly delivering the corresponding products, 3kB $(67 \%, 55: 45 d r)$ and 3IB $(75 \%, 51: 49 d r)$ with drastically lower diastereoselectivities. 
Subsequently, recrystallization of $\mathbf{3} \mathbf{a} \mathbf{B}$ was targeted and a monocrystal structure was obtained (Figure 1). Structural X-ray diffraction analysis allowed determination of the absolute configuration of the major diastereomer as $\left(S_{S}, S_{P}\right)$. The absolute configurations of other major diastereomers were attributed accordingly.

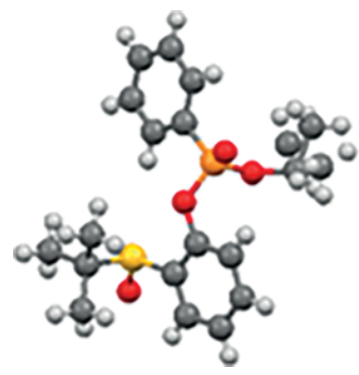

Figure 1. X-ray crystal structures of $3 a B\left(S_{S}, S_{P}\right)$.

Successively, our efforts have focused on post-modifications of these $P$-stereogenic compounds. Towards this goal both diastereomers of $\mathbf{3 g B}$ were separated by silica gel chromatography delivering the optically pure $\left(S_{S}, S_{\mathrm{P}}\right)$-3 $\mathbf{g B}$ and $\left(S_{\mathrm{S}}, R_{\mathrm{P}}\right)$-3g $\mathbf{B}$ in synthetically useful yields (33 and $35 \%$ yield of each diastereomer). With the diastereomerically pure $P$-precursors in hand, the postfunctionalization was attempted, using $\mathrm{MeMgBr}$ as nucleophile. Rewardingly, fully chemoselective transformation took place as selective cleavage of the sulfoxyde-phenyl 2B occured, delivering 4 in 64\% yield and 90:10 er. Importantly, the chiral auxiliary 2B could be recovered in $93 \%$ yield and excellent optical purity (ee 99:1) (Scheme 5).

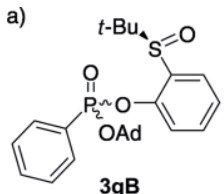

$3 \mathrm{gB}$

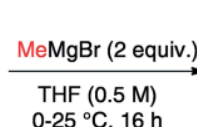

$0-25^{\circ} \mathrm{C}, 16 \mathrm{~h}$

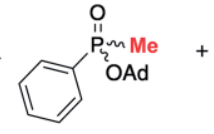

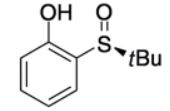

2B

$93 \%$, er $>99 / 1$ b)

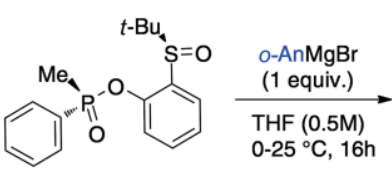

$\left(S_{\mathrm{S}}, R_{\mathrm{P}}\right)-3 \mathrm{BB}$

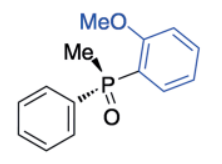

(S)-PAMPO

$84 \%$, er $>98 / 2$

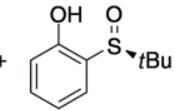

2B
Scheme 5. Post-functionalization of $3 \mathrm{gB}$ and $3 \mathrm{IB}$.

Furthermore, in order to showcase the synthetic utility of this methodology, we have embarked on designing a new protocol for the synthesis of PAMPO, key precursor for the synthesis of the seminal DIPAMP ligand. Towards this end diastereomerically pure sample of $\left(S_{S}, R_{P}\right)$-3IB was prepared via silica gel chromatography. This starting material was subsequently reacted with $0-\mathrm{AnMgBr}$ in $\mathrm{THF}$ and at $0{ }^{\circ} \mathrm{C}$, thus furnishing $\left(S_{\mathrm{P}}\right)$-PAMPO in excellent yield of $84 \%$. The optical purity of PAMPO, ee $>98 \%$ was confirmed by chiral HPLC analysis. Besides, the specific optical rotation measurement $\left\{[\alpha]_{D}^{20}=-9.74\left(c=0.5, \mathrm{CHCl}_{3}\right)\right\}$, by comparison with literature values, ${ }^{[2 b, 15]}$ indicates the $S$-configu- ration; this observation is consistent with the expected mechanism of the post-functionalization, occurring with inversion of the configuration at $P$-stereocenter. Besides, 2B was recovered as a single enantiomer in extremely high yield (94\%).

In summary we have developed a new diastereoselective O-P coupling. The use of the sulfoxide as chiral auxiliary allows performing this $\mathrm{P}-\mathrm{H}$ functionalization under modified Atherton-Todd conditions, at room temperature and in absence of a catalyst. The diastereoselectivity observed is moderate to high but the diastereomeric compounds may be separated in some cases, thus providing optically pure $P$-stereogenic scaffolds. Importantly, these new $P$-stereogenic scaffolds are interesting precursors for many other $P$-stereogenic molecules as post-modifications may be conducted. Accordingly, this new methodology allows synthesis of PAMPO, the key precursor of P-stereogenic ligands in very efficient and straightforward method.

\section{Acknowledgments}

We thank the Indo-French Centre for the Promotion of Advanced Research (IFCPAR/CEFIPRA) for financial support. A. M. is very grateful to CEFIPRA for a doctoral grant. We are also very grateful to Dr. Lydia Karmazin et Dr. Corinne Bailly for singlecrystal X-ray diffraction analysis.

Keywords: P-stereogenic phosphonate · O-P coupling Sulfoxide · Dynamic kinetic resolution - Tertiary phosphine oxide

[1] a) W. S. Knowles, R. Noyori, Acc. Chem. Res. 2007, 40, 1238-1239; b) P. W. N. M. van Leeuwen, P. C. J. Kamer, C. Claver, O. Pàmies, M. Diéguez, Chem. Rev. 2011, 111, 2077-2118; c) M. Dutartre, J. Bayardon, S. Jugé, Chem. Soc. Rev. 2016, 45, 5771-5794; d) T. Imamoto, Chem. Rec. 2016, 16, 2659-2673.

[2] a) A. Grabulosa, J. Granell, G. Muller, Coord. Chem. Rev. 2007, 251, 25-90; b) E. Bergin, C. T. O'Connor, S. B. Robinson, E. M. McGarrigle, C. P. O'Mahony, D. G. Gilheany, J. Am. Chem. Soc. 2007, 129, 9566-9567; c) C. M. Longo, Y. Wei, M. F. Roberts, S. J. Miller, Angew. Chem. Int. Ed. 2009, 484222-4225; Angew. Chem. 2009, 121, 4286; d) J. J. Gammon, V. H. Gessner, G. R. Barker, J. Granander, A. C. Whitwood, C. Strohmann, P. O'Brien, B. Kelly, J. Am. Chem. Soc. 2010, 132, 13922-13927; e) A. Grabulosa, P-Stereogenic Ligands in Enantioselective Catalysis, $1^{\text {st }}$ Ed. Catalysis Series 7 (Ed.: J. J. Spivey), RSC Publishing, 2011; f) J. Bayardon, S. Jugé, in Phosphorus(III) Ligands in Homogeneous Catalysis: Design and Synthesis (Eds.: P. C. J. Kamer, P. W. N. M. van Leeuwen), Wiley-Blackwell, 2012, pp. 355-389; g) Z. S. Han, N. Goyal, M. A. Herbage, J. D. Sieber, B. Qu, Y. Xu, Z. Li, J. T. Reeves, J. N. Desrosiers, S. Ma, J. Am. Chem. Soc. 2013, 135, 2474-2477; h) L. Copey, L. Jean-Gérard, E. Framery, G. Pilet, V. Robert, B. Andrioletti, Chem. Eur. J. 2015, 21, 9057-9061; i) D. A. DiRocco, Y. Ji, E. C. Sherer, A. Klapars, M. Reibarkh, J. Dropinski, R. Mathew, P. Maligres, A. M. Hyde, J. Limanto, Science 2017, 356, 426-430.

[3] a) V. S. Chan, I. C. Stewart, R. G. Bergman, F. D. Toste, J. Am. Chem. Soc. 2006, 128, 2786-2787; b) D. Gwon, D. Lee, J. Kim, S. Park, S. Chang, Chem. Eur. J. 2014, 20, 12421-12425; c) Y.-S. Jang, M. Dieckmann, N. Cramer, Angew. Chem. Int. Ed. 2017, 56, 15088-15092; Angew. Chem. 2017, 129, 15284; d) Y. Sun, N. Cramer, Angew. Chem. Int. Ed. 2017, 56, 364-367; Angew. Chem. 2017, 129, 370; e) Y.-S. Jang, Ł. Woźniak, J. Pedroni, N. Cramer, Angew. Chem. Int. Ed. 2018, 57, 12901-12905; Angew. Chem. 2018, 130, 13083; f) Y. Sun, N. Cramer, Chem. Sci. 2018, 9, 2981-2985.

[4] a) E. R. Francotte, J. Chromatogr. A 2001, 906, 379-397; b) D. Gatineau, D. H. Nguyen, D. Hérault, N. Vanthuyne, J. Leclaire, L. Giordano, G. Buono, J. Org. Chem. 2015, 80, 4132-4141. 
[5] O. Korpiun, K. Mislow, J. Am. Chem. Soc. 1967, 89, 4784-4786.

[6] a) W. S. Knowles, M. J. Sabacky, B. D. Vineyard, D. J. Weinkauff, J. Am. Chem. Soc. 1975, 97, 2567-2568; b) B. D. Vineyard, W. S. Knowles, M. J. Sabacky, G. L. Bachman, D. J. Weinkauff, J. Am. Chem. Soc. 1977, 99, 5946-5952; C) Y. Yamanoi, T. Imamoto, J. Org. Chem. 1999, 64, 29882989.

[7] a) S. Juge, J. P. Genet, Tetrahedron Lett. 1989, 30, 2783-2786; b) S. Juge, M. Stephan, J. A. Laffitte, J. P. Genet, Tetrahedron Lett. 1990, 31, 63576360 ; c) S. Jugé, Phosphorus Sulfur Silicon Relat. Elem. 2008, 183, 233248.

[8] A. D'Onofrio, L. Copey, L. Jean-Gérard, C. Goux-Henry, G. Pilet, B. Andrioletti, E. Framery, Org. Biomol. Chem. 2015, 13, 9029-9034.

[9] A. R. Muci, K. R. Campos, D. A. Evans, J. Am. Chem. Soc. 1995, 117, 90759076.

[10] S. S. L. Corre, M. Berchel, H. Couthon-Gourvès, J.-P. Haelters, P.-A. Jaffrès, Beilstein J. Org. Chem. 2014, 10, 1166-1196.

[11] a) B. Xiong, Y. Zhou, C. Zhao, M. Goto, S.-F. Yin, L.-B. Han, Tetrahedron 2013, 69, 9373-9380; b) Y. Zhou, G. Wang, Y. Saga, R. Shen, M. Goto, Y. Zhao, L.-B. Han, J. Org. Chem. 2010, 75, 7924-7927.

[12] a) Y. Tang, Y. Sun, J. Liu, S. Duttwyler, Org. Biomol. Chem. 2016, 14, 55805585; b) P. Wang, J. Chen, L. Cun, J. Deng, J. Zhu, J. Liao, Org. Biomol. Chem. 2009, 7, 3741-3747.
[13] G. Javierre, R. Fortrie, M. Jean, D. Moraleda, J.-V. Naubron, F. Fotiadu, J. Mol. Model. 2017, 23, 168.

[14] a) M. Schuman, X. Lopez, M. Karplus, V. Gouverneur, Tetrahedron 2001, 57, 10299-10307; b) S. Deprèle, J.-L. Montchamp, J. Organomet. Chem. 2002, 643-644, 154-163; c) H. Xu, K. Ekoue-Kovi, C. Wolf, J. Org. Chem. 2008, 73, 7638-7650; d) G. Keglevich, E. Jablonkai, L. B. Balázs, RSC Adv. 2014, 4, 22808-22816; e) K. Bravo-Altamirano, L. Coudray, E. L. Deal, J.L. Montchamp, Org. Biomol. Chem. 2010, 8, 5541-5551; f) O. Berger, C. Petit, E. L. Deal, J.-L. Montchamp, Adv. Synth. Catal. 2013, 355, 13611373; g) E. Jablonkai, R. Henyecz, M. Milen, J. Kóti, G. Keglevich, Tetrahedron 2014, 70, 8280-8285; h) R. Beaud, R. J. Phipps, M. J. Gaunt, J. Am. Chem. Soc. 2016, 138, 13183-13186; i) J. M. Cross, N. Gallagher, J. H. Gill, M. Jain, A. W. McNeillis, K. L. Rockley, F. H. Tscherny, N. J. Wirszycz, D. S. Yufit, J. W. Walton, Dalton Trans. 2016, 45, 12807-12813.

[15] a) See ref. ${ }^{[2 b]}$; b) H. Adams, R. C. Collins, S. Jones, C. J. A. Warner, Org. Lett. 2011, 13, 6576-6579. 